\title{
ANTECEDENTES HISTÓRICOS DE LA RESPONSABILIDAD PENAL DE LAS PERSONAS JURÍDICAS*
}

\author{
ANTECEDENTES HISTÓRICOS DA RESPONSABILIDADE PENAL \\ DAS PESSOAS JURÍDICAS \\ HISTORICAL ANTECEDENTS OF THE CRIMINAL RESPONSIBILITY \\ OF LEGAL PERSONS

\section{LUCAS GABRIEL MENÉNDEZ CONCA**}

Recibido: 30 de noviembre de 2020 - Aceptado: 30 de mayo de 2021 -

Publicado: 30 de junio de 2021

DOI: $10.24142 /$ raju.v16n32a4

\section{Resumen}

En este trabajo se analiza, de forma breve, el origen y la evolución de la responsabilidad penal de las personas jurídicas a lo largo de los siglos, comenzando por el derecho romano y examinando después

\footnotetext{
* $\quad$ Este texto se inserta dentro de las líneas de investigación del Grupo de Estudios Penales de la Universidad de Zaragoza, grupo de investigación de referencia reconocido por la Comunidad Autónoma de Aragón (BOA de 27 de marzo de 2017), cuyo Investigador Principal es el Prof. Dr. D. Miguel Ángel Boldova Pasamar, Catedrático de Derecho Penal de la Universidad de Zaragoza.

** Investigador predoctoral del Grupo de Estudios Penales de la Universidad de Zaragoza y alumno del programa de Doctorado en Derechos Humanos y Libertades Fundamentales de la Universidad de Zaragoza. Grado en Derecho, Universidad Nacional de Educación a Distancia (UNED), y Máster Universitario en Abogacía, Universidad de Zaragoza. ORCID: https://orcid.org/0000-00018562-1487; Google Scholar: https://scholar.google.com/citations?user=84btzwEAAAAJ\&hl=es. Correo electrónico: lucasmenendez@unizar.es
} 
el derecho medieval y el derecho canónico, hasta llegar al debate de esta cuestión en el siglo XIX. Aunque frecuentemente se ha presentado como obvio y vetusto el principio societas delinquere non potest, lo cierto es que su formulación no puede remontarse más allá del siglo XVIII o de la primera mitad del siglo XIX, habiendo dominado en los precedentes siete siglos la idea opuesta: universitas delinquere et puniri potest. En efecto, durante los siglos anteriores al siglo XIX se admitía la capacidad criminal de las corporaciones y, por ende, la posibilidad de declarar su responsabilidad penal por la comisión de un delito. La discusión dogmática se centraba especialmente en la cuestión de si las corporaciones, como entes sin alma, podían ser castigadas con penas espirituales como la excomunión.

Palabras clave: antecedentes históricos, responsabilidad penal de las personas jurídicas, empresa, derecho penal.

\section{Abstract}

This paper briefly analyzes the origin and evolution of Corporate Criminal liability over the centuries, beginning with Roman Law and then examining medieval law and canon law, until reaching the debate on this question in the nineteenth century. Although the principle societas delinquere non potest has frequently been showed as obvious and outdated, its formulation cannot go back beyond the eighteenth century or the first half of the $19^{\text {th }}$ century having dominated in the preceding seven centuries the opposite idea universitas delinquere et puniri potest. Indeed, during the centuries prior to the $19^{\text {th }}$ century, the criminal capacity of corporations was admitted and, therefore, the possibility of declaring their criminal liability for the commission of a crime. At that time the discussion focused especially on whether corporations, as soulless entities, could be punished with spiritual punishment such as excommunion. This work is inserted within the research lines of the Criminal Studies Group of the University of Zaragoza.

Keywords: historical background, corporate criminal liability, corporations and criminal law. 


\section{Resumo}

Este trabalho analisa brevemente a origem e evolução da responsabilidade penal das pessoas jurídicas ao longo dos séculos, começando pelo Direito Romano e passando pelo Direito medieval e pelo Direito Canônico, até chegar ao debate sobre essa questão, no século XIX. Embora o princípio societas delinquere non potest tenha sido frequentemente apresentado como óbvio e desatualizado, a verdade é que sua formulação não pode ir além do século XVIII ou da primeira metade do século XIX, tendo a ideia oposta universitas dominado nos sete séculos precedentes. delinquere et puniri potest. Com efeito, durante os séculos anteriores ao século XIX, foi admitida a capacidade criminosa das empresas e, portanto, a possibilidade de declarar a sua responsabilidade criminal pela prática de um crime. A discussão dogmática focou especialmente na questão de saber se as corporações, como entidades sem alma, poderiam ser punidas com penalidades espirituais, como a excomunhão. Este trabalho está inserido nas linhas de pesquisa do Grupo de Estudos Criminais da Universidade de Zaragoza.

Palavras-chave: antecedentes históricos, responsabilidade penal das pessoas jurídicas, direito empresarial e penal. 


\section{INTRODUCCIÓN}

Durante los últimos años, un cada vez mayor número de países han previsto en sus ordenamientos jurídicos la posibilidad de hacer responsables penalmente a las personas jurídicas por los delitos cometidos en su nombre o por su cuenta y en su beneficio. Aunque muchos países, entre ellos España, se vieron reticentes a romper con su tradición jurídica de no reconocer capacidad delictiva a las personas jurídicas, lo cierto es que la teoría de que las corporaciones no pueden delinquir constituye realmente una excepción a la larga evolución histórica que ha tenido este régimen de responsabilidad penal. En efecto, la doctrina penal contemporánea de Europa continental ha presentado frecuentemente como obvio y vetusto el principio societas delinquere non potest, $\mathrm{o}$, expresado también de otro modo, universitas delinquere nequit. Sin embargo, como pone de manifiesto Marinucci (2008), "su formulación no puede remontarse más allá del siglo XVIII o de la primera mitad del XIX, habiendo dominado en los precedentes siete siglos la idea opuesta universitas delinquere et puniri potest" (p. 1173).

Por ello, es conveniente exponer, aunque sea de forma breve, cómo se recogía antiguamente la responsabilidad penal colectiva y cómo ha devenido a lo largo del tiempo en el reconocimiento de la capacidad criminal de las corporaciones. Aunque es innegable el desarrollo que el derecho angloamericano ha otorgado a este régimen de responsabilidad penal durante los últimos dos siglos, no podemos caer en el equívoco de creer que la responsabilidad penal de las personas jurídicas (en adelante RPPJ) es una creación suya, puesto que la responsabilidad de los entes colectivos ha existido en el derecho de la Europa continental durante los siete siglos anteriores al siglo XIX y tiene sus orígenes más remotos en textos antiquísimos (Busato, 2019, p. 20; Marinucci, 2008, p. 1183 y Ortiz de Urbina, 2014, p. 36).

El Código de Hammurabi, escrito en 1750 a. C. por el rey de Babilonia Hammurabi, recoge dos tipos de responsabilidad colectiva, la responsabilidad familiar, en virtud de la cual los miembros de la familia pueden responder personalmente por los daños ocasionados por su pariente (se correspondería con la expresión de la ley del talión "ojo por ojo, diente por diente"), y la responsabilidad de la corporación territorial, en la que se prevé la responsabilidad de la ciudad por los actos delictivos cometidos por sus ciudadanos: 
Art. 22: Si uno ejerció el bandidaje y es atrapado, recibirá la muerte.

Art. 23: Si el bandido no fue apresado, el hombre despojado prestará juramento de todo lo que ha sido despojado, y la ciudad y el jeque en cuyos límites fue el despojo, le devolverán todo lo que perdió.

Art. 24: Si se trata de una persona, la ciudad y el jeque pagarán una mina de plata (citado en Martínez, 2018, p. 41).

Este es el primer ejemplo histórico legal de responsabilidad penal corporativa, concretamente de corporaciones territoriales, el cual ha estado vigente, al menos, hasta la Revolución francesa (Martínez, 2018, pp. 40-42).

En la Biblia se hace referencia al conocido castigo de Sodoma y Gomorra, ciudades pecaminosas que sufrieron colectivamente la justicia divina. También encontramos la historia de la ciudad de Nínive, la cual iba a ser destruida, pero sus habitantes persistieron en sus pecados, purgaron su culpa y fueron perdonados. Resulta conveniente citar estos dos supuestos, ya que los textos bíblicos son una de las principales fuentes del derecho de la Edad Media y la Edad Moderna (Martínez, 2018, p. 35 y ss.).

El derecho griego también ofrece ejemplos de solidaridad penal, que en unos casos consiste en un deber solidario de vengar la ofensa sufrida y, en otros, en un deber solidario de responder por el daño causado. De este modo, van surgiendo en Grecia diversos tipos de solidaridad penal: familiar, local, nacional, etc. Como indica Saldaña (1927), rige en Grecia un tipo de solidaridad penal familiar, puesto que

carece de valor —y de valor jurídico penal— el individuo, si no está asociado, englobado, en una familia; porque toda ofensa repercute en ella, y solo ella reacciona, como un solo cuerpo multitudinario, inervándose para la venganza, $\mathrm{y}$, opuestamente, respondiendo del crimen (pp. 87-88).

\section{DERECHO ROMANO CLÁSICO}

Por la trascendencia que ha tenido su tratamiento de la responsabilidad colectiva, es necesario referirse al derecho romano clásico. A pesar de que el derecho romano desconocía el concepto de persona jurídica, tal como hoy es entendido (Cantarella, 2017, p. 208 y Fernández, 2019, p. 155), ya en la época clásica existían conjuntos de personas a los que se les reconocían ciertos derechos subjetivos. En esos casos, la suma de sus miembros era 
considerada la titular de los derechos, por lo que la desaparición de uno de sus integrantes no afectaba la continuidad de la corporación (Bacigalupo, 1998, p. 43). En este sentido, Ferrara (1929) afirma que

la corporación, como cosa ideal, subsiste, aunque los miembros varíen, y si se reducen a uno, la corporación permanece sin confundirse con este último. [...] En Derecho romano la antítesis entre universitas y singuli es rígidamente conducida hasta sus últimas consecuencias: entre la corporación y los asociados hay un abismo; ningún vínculo se produce entre ellos, aquella es una extraña respecto de estos (pp. 33 y 118-119).

La universitas era un ente distinto de la pluralidad de sus miembros, un sujeto diferente creado al lado de los particulares reunidos en asociación, al que se le reconocían derechos patrimoniales. Se distinguían los derechos y las obligaciones de la corporación (universitas) y los de cada uno de sus miembros (singuli) (Ferrara, 1929, pp. 34-35 y González-Varas, 2007, p. 41).

En esta época, la corporación más importante era el municipio, esto es, la ciudad de la provincia, ente contra el que, según Ulpiano (Digesto 4, $3,15,1)$, se podía ejercer la actio de dolo malo, la acusación, cuando el perceptor de impuestos había engañado a una persona enriqueciendo al mismo tiempo a la ciudad. En este caso, los habitantes de la ciudad estaban obligados a devolver la cantidad obtenida ilícitamente (Bacigalupo, 1998, p. 43). No obstante, Ulpiano declara que solo cabe reclamar por la conducta de sus administradores o perceptores de impuestos, por el lucro obtenido, pero no por un hecho propio de la corporación (De Simone, 2012, p. 40; Escrihuela, 2019, p. 71 y Pérez, 2014, p. 50):

Pero dudase si se da la acción de dolo contra los Municipios. Y opino, que, a la verdad, no puede darse por su dolo; porque ¿qué pueden hacer con dolo los Municipios? Pero si algún lucro les ha alcanzado por el dolo de los que administran sus bienes, juzgo que debe darse. Más por el dolo de los Decuriones se dará la acción de dolo contra los mismos Decuriones (Digesto 4, 3, 15, 1, citado en Pérez, 2014, p. 50).

Las dudas interpretativas que presentan los dos únicos extractos del Digesto, que se refieren a la responsabilidad penal corporativa en el derecho romano (de dolo malo y quod metus causa), han permitido hallar razones tanto a quienes consideran que Roma conoció tal régimen de responsabili- 
dad penal como a quienes defienden la tesis contraria (Martínez, 2018, p. 53 y ss.). Por ello, dejando a un lado estas dudas interpretativas, Martínez considera que hay al menos dos instituciones en las que se puede basar la hipótesis de que en Roma existió responsabilidad penal corporativa. Se refiere, en primer lugar, a los supuestos de destrucción o pérdida de derechos de las ciudades. Un ejemplo sería el caso de la ciudad de Capua, que abandonó a Roma durante la segunda guerra púnica y, tras la paz, perdió su constitución municipal y sus principales habitantes fueron ejecutados. La otra institución que pone de manifiesto la ideología romana relativa a los castigos colectivos es el diezmo, un castigo que se imponía en los ejércitos romanos, según el cual, la pena la sufría toda la legión o toda la cohorte, mediante la ejecución por sorteo de un hombre de cada diez. Martínez (2018) indica que

\begin{abstract}
tanto el castigo como la pena eran colectivos, si bien por una cuestión puramente práctica la pena colectiva se aplicaba solo sobre un sujeto, siendo que los otros nueve sufrían la pena "mitigada" de haber estado en riesgo de muerte, de recibir malos alimentos y de no poder dormir en el campamento (pp. 62-65).
\end{abstract}

Como pone de manifiesto este autor, las dos instituciones permiten constatar que en el derecho romano los castigos colectivos y corporativos eran frecuentes. Estos datos, unidos al hecho de que la responsabilidad penal corporativa habría existido en las civilizaciones anteriores, contemporáneas y posteriores a Roma, hacen que resulte difícil negar la existencia de este régimen de responsabilidad penal en el derecho romano (Martínez, 2018, pp. 64-65).

\title{
DERECHO MEDIEVAL Y DERECHO CANÓNICO
}

El derecho que regía los pueblos germánicos que invadieron el Imperio romano de Occidente no alcanzó nunca la concepción de un ente ideal distinto de la colectividad de los individuos asociados. Para lograr ello se requería una fuerza de abstracción de la que no eran capaces estos pueblos primitivos. El derecho germánico no ve en las asociaciones más que una pluralidad de personas que poseen bienes comunes (Ferrara, 1929, p. 42; Morales, 2000, p. 128 y Serrano, 1988, p. 142).

Al comienzo de la Edad Media las corporaciones adquieren mayor relevancia al ser titulares tanto de poder político como de funciones económicas, por lo que el Estado se ve obligado a responder frente a los atentados contra el orden social que tienen su origen en el ámbito de poder de esas 
corporaciones (Bacigalupo, 1998, p. 45). Con la fundación de la Escuela de Bolonia en el año 1088 se recupera el cultivo del derecho romano. Sus integrantes comienzan a escribir notas o comentarios en aquellos textos romanos cuya interpretación no resultaba evidente. Esas notas o glosas son precisamente las que dan nombre a la conocida "Escuela de los glosadores", que desenvolvió su actividad hasta el siglo XIII (Martínez, 2018, pp. 74-75).

Aunque los glosadores, al igual que los romanos, no elaboran una teoría de la persona jurídica, consideran que las corporaciones son capaces de delinquir. Para identificar cuándo se está ante un delito de la corporación, o solamente ante un delito de uno de sus miembros, los glosadores se basan en los principios del derecho romano. Como señala Bacigalupo (1998), "existía un delito de la corporación, cuando la totalidad de sus miembros daba comienzo a una acción penalmente relevante por medio de una toma de decisión conjunta" (p. 46). Esta se producía cuando la decisión de llevar a cabo tal acción

se tomaba en una reunión de los miembros de la corporación o sobre la base de una decisión del conjunto de los mismos. La acción realizada con base en la decisión de la mayoría era equiparada también con la acción del conjunto (p. 46).

Si no había una decisión conjunta, la acción delictiva era imputada individualmente a los perceptores de impuestos, a los administradores o a cualquier miembro responsable de su realización. No obstante, el delito cometido de forma individual por uno de los integrantes de la corporación repercutía sobre la totalidad de los miembros si posteriormente era aprobado por estos.

En un momento histórico en el que la figura de la Iglesia cobra relevancia y es considerada como el punto central de la corporación, los canonistas comienzan a elaborar un concepto técnico-jurídico de persona jurídica. Para fundamentar la capacidad jurídica de la Iglesia, cuyos derechos no pertenecían a la totalidad de sus fieles, sino a Dios, estos juristas aceptan la concepción romana de la capacidad jurídica de la universitas, separada conceptualmente de la capacidad jurídica del singuli. Los canonistas desarrollan una teoría específica de la corporación eclesiástica entendiéndola como "persona" y convertida de este modo en el sujeto de derecho. Distinguen el concepto jurídico de persona del concepto real de la persona como ser humano. Conforme a esta teoría, la universitas es jurídicamente algo distinto de 
los singuli que la componen: es un ser incorporal que solo posee capacidad jurídica por medio de la ficción jurídica (Bacigalupo, 1998, pp. 47-48). Por ello, admiten la identidad de esta corporación, aunque cambien las personas que la componen, y consideran que la misma perdura incluso si desaparecen todos sus miembros (Ferrara, 1929, p. 71 y González-Varas, 2007, pp. 78-79). Los derechos de la universitas y los de los singuli se distinguen en este momento de forma clara. La teoría que mantienen los canonistas, especialmente Sinibaldo de Fieschi, de la universitas como una persona ficta, influye decisivamente en la concepción moderna de la corporación. Es en este momento en el que empieza a elaborarse el concepto de persona jurídica.

En esta época los emperadores y los papas abusaban del empleo de penas graves (la excomunión y el entredicho) contra las ciudades y las corporaciones que les oponían resistencia, lo que implicaba que todas las personas que formaban parte del colectivo afectado recibían el mismo castigo espiritual, independientemente de su participación individual en el hecho delictivo. Este régimen punitivo suponía, por tanto, una gran injusticia a la que se enfrentarían los juristas que consideraban que la universitas no podía ser excomulgada. El rechazo a la excomunión de ciudades y corporaciones partía de que se trataba de una pena espiritual que solo se podía aplicar a bautizados y, obviamente, las ciudades y las corporaciones no lo estaban. No podían estarlo, pues carecían de alma (Bueno, 2014, p. 19; De Castro y Bravo, 1981, pp. 146 y 262-263 y Serrano, 1988, p. 157). Este tema fue tratado en el I Concilio de Lyon de 1245, en el que se impuso la tesis de Sinibaldo de Fieschi, el papa Inocencio IV, de que la excomunión era una pena espiritual y que, por tanto, no podía aplicarse a entes sin alma inmortal, como eran las ciudades y las universitates (De Castro y Bravo, 1981, pp. 147-148 y 262-263; De Simone, 2012, pp. 44-45 y González-Varas, 2007, pp. 86-87). Su oposición a la posibilidad de imponerles tal pena resulta patente en su comentario a la Decretal de Honorio III Gravem Venerabilis Fratris, en la que se recoge la condena a la ciudad de Pisa. El pueblo y la potestas de dicha ciudad nombraron comisionados para hacer los estatutos de la misma, pero los comisionados, excediéndose del mandato que habían recibido, redactaron sus estatutos perjudicando a la Iglesia. Como castigo por tales actos, Honorio III excomulgó a toda la ciudad. En su comentario a dicha decretal, Inocencio IV discrepa de la postura de su antecesor y reafirma su tesis contraria.

Aunque Sinibaldo de Fieschi es ensalzado como el hombre que influyó decisivamente desde su posición de papa a fin de prohibir la excomunión de ciudades y universitas (Capilla, 1984, p. 35; y Serrano, 1988, p. 199), 
postura que fue seguida por los juristas que le sucedieron (Bueno, 2014, p. 23 y ss.), se discute la cuestión de si este autor, a diferencia de la mayoría de los canonistas, defendía que la universitas no tenía capacidad para cometer delitos. La interpretación tradicional de que Inocencio IV negaba la posibilidad de que las corporaciones tuvieran capacidad de acción criminal y, por tanto, pudieran incurrir en responsabilidad penal por el delito cometido, tendría principalmente como base su conocida frase impossibile est quod universitas delinquat. También se apoya esta interpretación en el hecho de que Inocencio IV defendía la teoría en virtud de la cual las corporaciones son meras ficciones jurídicas (nomina iuris), ya que la propia esencia ficticia de la corporación acarrearía su incapacidad delictiva (Martínez, 2018, p. 92). No obstante, durante los últimos años se han alzado varios autores en defensa de la tesis de que Inocencio IV no negaba la capacidad de acción criminal de la corporación, ni tampoco su responsabilidad penal, sino únicamente la posibilidad de que pudiese sufrir el castigo de la excomunión.

En efecto, Martínez (2018, p. 91 y ss.), siguiendo a Panizo (1975, p. 343 y ss.), señala que la simple literalidad de la frase impossibile est quod universitas delinquat, contenida en el primer párrafo de su comentario a la Decretal de Honorio III Gravem Venerabilis Fratris, aislada del resto del texto de Inocencio IV, podría inducir al error de pensar que él fue un firme partidario de la imposibilidad de la responsabilidad penal corporativa. También consideran que Inocencio IV no negaba la capacidad delictiva de la universitas (Minasola, 2015, pp. 18-19 y Serrano, 1988, p. 198 y ss.). Ullmann ya había anticipado esta interpretación de la obra de Inocencio iv en su artículo "The Delictal Liability of Medieval Corporations", publicado en The Law Quarterly Review en el año 1948.

En palabras de Martínez (2018):

Inocencio IV [...] no pretende dar una doctrina general sino simplemente resolver el caso concreto de la ciudad de Pisa. Así, lo que estaría destacando Inocencio (actuando como juez) es que no tiene sentido plantearse si delinquió o no, pues dado que lo que se pretende saber es si Pisa debe o no ser excomulgada, y siendo la excomunión imposible, no es necesario realizar ningún planteamiento previo. $\mathrm{Y}$ tampoco tiene sentido en este caso concreto plantearse una pena diferente para la universitas, porque los hechos parten de que los rectores se extralimitaron en el mandato, situación que en todo caso excluye la responsabilidad criminal de la universitas (p. 98). 
Continúa diciendo Martínez (2018), que en el tercer párrafo de su comentario a la Decretal de Honorio III, Inocencio IV

explica las condiciones para que la corporación sea reconocida como culpable de un delito y en consecuencia castigada. Párrafo que supondría una contradicción notabilísima si, de acuerdo con la communis opinio, sostuviéramos el carácter axiomático de la frase del primer párrafo contra toda responsabilidad penal corporativa (p. 98).

Por tanto, la contundente frase de Inocencio IV contenida en el primer párrafo de su comentario no se refiere a cualquier tipo de delito, sino que, como afirma Serrano (1988),

se circunscribe al caso en que se está refiriendo en el texto citado. Es decir, según esta actitud lo que nos estaría diciendo Sinibaldo no es que la "universitas" no puede delinquir nunca en un sentido absoluto, sino que no puede delinquir en relación con la pena de excomunión. Para ser más exactos, que no puede cometer un delito penado con el citado castigo (p. 217).

Por tanto, Inocencio IV no negaba la capacidad delictiva de las corporaciones, sino la posibilidad de que pudiesen ser excomulgadas por la propia naturaleza de esta pena: solo la persona individual es capaz de excomunión, pues solo ella es capaz de recibir sacramentos (Martínez, 2018, p. 101). En su comentario, este jurista plantea el supuesto del mandato de la universitas para delinquir. Se produciría cuando los rectores o representantes de la universitas cometan un delito en nombre de la misma, o bien cuando la universitas ratifique con posterioridad lo que sin mandato había sido realizado en su nombre. En ambos casos, Inocencio IV admite la existencia de delito de la universitas, puesto que la hace titular del castigo (D'Alessandro, 2015, p. 16; De Simone, 2012, p. 45; Minasola, 2015, p. 18 y Panizo, 1975, p. 364).

Al igual que los glosadores, los canonistas estiman que se está en presencia de un delito de la corporación cuando existe una acción conjunta de sus miembros llevada a cabo por medio de una toma de decisión de todos ellos. La decisión de la mayoría también afecta a la corporación y a sus integrantes. Estos juristas distinguen claramente entre la universitas y los singuli, por lo que también diferencian entre la responsabilidad de la corporación y la de las personas que la integran. Ambas responsabilidades eran sometidas a un proceso penal en el que la universitas y sus miembros eran 
sometidos a las mismas reglas, con la única particularidad de que la corporación era representada, mientras que el individuo en cuestión no podía serlo (Bacigalupo, 1998, p. 51).

Los posglosadores, también llamados comentaristas, aceptaron la teoría de los canonistas de que la universitas era una persona ficta y admitieron también la posibilidad de que la misma pudiese cometer delitos. Entre ellos se destaca, en el siglo XIV, Bártolo de Sassoferrato, quien fundamentaba la capacidad delictiva de la universitas con una fictio iuris. La universitas es un ente distinto de la mera suma de los miembros que la componen. La ficción consiste en llamar persona a algo que, desde luego, no cumple la condición esencial de la misma, como es la sustancia racional individual. Conforme a esta concepción, la corporación permanece siempre la misma, aunque varíen sus componentes (De Castro y Bravo, 1981, pp. 153-154 y Serrano, 1988, pp. 231-232). Este autor distingue los delitos que la universitas puede llevar a cabo de forma proprie, que serían los delitos omisivos de los miembros de la corporación, así como aquellas acciones que se encuentran estrechamente relacionadas con la esencia y el ámbito especial de deberes de una corporación (Bacigalupo, 1998, p. 52 y De Simone, 2012, p. 46):

Si se pregunta si la corporación delinque, digo que la corporación puede cometer pecado de omisión. [...] Hay algunas cosas que solo pueden hacerlas las corporaciones, como hacer estatutos, dar jurisdicción, imponer colectas y otras similares. En este caso la corporación puede delinquir (Commentarium ad Digestum Novum 48, 19, 16, 10, 2, citado en Martínez, 2018, pp. 121-122).

La universitas delinque de forma impropie en aquellos supuestos en que la acción no tenga que ver directamente con su derecho propio, siempre y cuando se cumplan ciertos requisitos (De Simone, 2012, p. 46 y Martínez, 2018, p. 122):

Los hechos que no tienen que ver con el propio derecho de la corporación, como cometer un homicidio, violencias o similares, la corporación no puede hacerlos propiamente, porque requieren a una persona verdadera. Pero se dice que los comete impropiamente a través de otros, regentes de la ciudad o por otros con vigor estatutario a través de los que la ciudad cometió el delito. [...] La corporación parece que comete el delito cuando se hizo con propósito deliberado y en un consejo se decide; en otro caso no se dice que la corporación lo haya hecho, sino que lo hicieron las personas individuales (Commentarium ad Digestum Novum 48, 19, 16, 10, 2, citado en Martínez, 2018, pp. 122-123). 
En caso de que no haya una decisión conjunta de los integrantes de la corporación para cometer el delito, habrá de castigarse individualmente a aquellos miembros que decidan realizarlo. Por tanto, la universitas puede cometer delitos por omisión y por acción, si bien entre estos últimos habrá algunos que los realice propiamente y otros impropiamente si se cumplen los requisitos señalados (Barbero, 1957, p. 298; D’Urso, 2000, pp. 544-545 y Minasola, 2015, p. 93 y ss.).

Bártolo de Sassoferrato estima que las corporaciones solo pueden sufrir penas que no sean corporales, pues en caso contrario se castigaría indistintamente a culpables e inocentes, e incluso a las personas que formaron parte de la corporación y han fallecido, y a aquellas otras que aún no han nacido y vendrán a integrar la misma en el futuro. Sin embargo, este jurista establece una excepción a esta regla general y admite que la corporación sufra un castigo corporal por la comisión de los delitos de lesa majestad humana y lesa majestad divina. A tal efecto, pone el ejemplo de la destrucción de la ciudad de Brescia, que finalmente mediante indulto del emperador recibió una pena más leve, y el de la destrucción de la orden de los templarios (D’Urso, 2000, pp. 546-547 y Martínez, 2018, pp. 123-124). Por último, este jurista se plantea la cuestión de si deben ser castigados simultáneamente o no la universitas y sus miembros, y responde que ello dependerá de si se trata de un delito propio o impropio. En caso de que se trate de un delito propio, la corporación puede ser castigada como autor y el resto de personas singulares podrán ser castigadas como instigadores o cómplices. En cambio, si estamos ante un delito impropio, la solución es la contraria. Es decir, se castiga a los individuos como autores del delito y a la corporación como cómplice (Martínez, 2018, pp. 124-125).

\section{EL DEBATE DE LA RPPJ EN EL SIGLO XIX}

Durante los siglos precedentes al siglo XIX había sido frecuente el castigo a las ciudades y las corporaciones. Así, por ejemplo, en Francia podemos citar el caso de la ciudad de Montpellier, que en 1379 se sublevó, con ocasión de un impuesto real, asesinando a funcionarios reales en la revuelta. Como castigo, la ciudad fue privada de su universidad, del consulado, de la casa comunal y de todos sus privilegios; se vio obligada a pagar una multa de 600.000 liras de oro, una parte de sus murallas fueron abatidas y sus fosas fueron rellenadas; además, seiscientos de entre sus habitantes más culpables fueron ejecutados. Otros ejemplos franceses los encontramos, ver- 
bigracia, en las penas impuestas a las ciudades de Toulouse (1331) y de Burdeos (1548), al condado de Beaufort (1567) y al pueblo de Goumée (1576). Incluso, la Sorbona fue condenada en 1561 por no haber sometido a control el contenido subversivo de una tesis doctoral. En 1607 la ciudad alemana de Donauwörth fue privada de su derecho de ciudad libre y de ciudad cabeza de provincia. En este mismo país, la ciudad de Magdeburgo fue destruida en 1631 como castigo por rebelarse contra el emperador. También se puede nombrar el castigo de los municipios de Grosselfingen y Hausen en 1739 (Amalfitano, 2014, p. 14 y ss. y Marinucci, 2008, pp. 1179-1182 y 1191).

Sin embargo, con el paso del tiempo los procesos penales contra universitas se hicieron cada vez menos frecuentes debido a la primacía del poder de los señores y del absolutismo, y a la correlativa pérdida del poder y la importancia que las corporaciones habían tenido durante la Edad Media, lo cual hizo innecesarias medidas tan gravosas como la condena de municipios enteros o de otras agrupaciones de personas. Había desaparecido la necesidad práctica y política de una pena para las asociaciones, lo cual favoreció que hallasen resonancia las objeciones teóricas que se habían formulado a este régimen de responsabilidad penal (De Simone, 2012, pp. 50-51; Hirsch, 1993, p. 1102 y Marinucci, 2008, p. 1180).

Estas objeciones teóricas se vieron impulsadas por el inicio de la Revolución francesa en 1789. Con la llegada del Iluminismo y del derecho natural, el individuo adquiere un lugar determinante del orden social, puesto que la finalidad última de esta organización consiste en garantizar al individuo la autodeterminación y la libertad respecto de condicionamientos supraindividuales. La idea de autodeterminación y libertad del individuo resulta incompatible con la responsabilidad que no se basa en un hecho propio, sino en la pertenencia a una comunidad o asociación. Se rechaza, en consecuencia, todo tipo de responsabilidad colectiva (Bacigalupo, 1998, p. 54 y Echarri, 2003, p. 29). No obstante, la supresión de la responsabilidad penal corporativa no fue consecuencia del auge de los derechos humanos, sino de la propia proscripción de las corporaciones en el ordenamiento francés. El 2 de marzo de 1791 se aprobó en la Asamblea el Decreto de Allarde, también conocido como Ley de Allarde, en cuyo artículo segundo se recogía la supresión de las corporaciones, y el 14 de junio de 1791 se dictó la Ley Le Chapelier, cuyo fin era evitar el riesgo de que una vez suprimidas las corporaciones surgieran instituciones parecidas con independencia de que utilizaran formas diferentes (Martínez, 2018, p. 233 y ss.). A partir del 1 de abril de 1791, en el que entra en vigor la Ley de Allerde, debe entenderse 
que las corporaciones, al desaparecer, dejan de tener responsabilidad penal. No obstante, como advierte Martínez (2018), ello no afecta en absoluto a "la responsabilidad penal de los otros tipos de universitates: territoriales (communautés), sin ánimo de lucro (corps) y las que quedaban con ánimo de lucro, sociedades y compañías (sociétés y compagnies)" (p. 244). En Francia ha sido el Código Napoleónico de 1810, uno de los monumentos legislativos de su época, el primero en excluir deliberadamente la responsabilidad penal de la persona jurídica (Busato, 2019, p. 49).

Uno de los primeros autores que se pronunció en contra de la RPPJ fue Julius von Malblanc, quien negaba en su escrito Opúsculo ad tus Crimínale Expectantia (1793) no solo la capacidad de la persona jurídica para cometer delitos, sino también para comprender la aplicación de la pena. La responsabilidad de la corporación es realmente una responsabilidad de sus miembros. Sin embargo, ello solo sería plenamente posible si tanto la imputación como la pena - desde el punto de vista de un derecho penal individualtambién alcanzara a todos los integrantes de la persona jurídica. Incluso los miembros futuros (posteri) deberían sufrir la pena. Sin embargo, a los miembros futuros no cabe imputarles ni el dolo ni la culpa por un hecho ya cometido, por lo que la responsabilidad penal de la persona jurídica es insostenible (Bacigalupo, 1998, pp. 54-55 y Echarri, 2003, p. 29). Por su parte, Anselm von Feuerbach rechazaba la posibilidad de que la persona jurídica pudiese ser sujeto activo de un delito, incluso en el caso de que todos sus miembros hubiesen querido y realizado el delito, puesto que no actuarían realmente como asociación, ya que la comisión del delito no se realizaría con la finalidad de la asociación, sino con una distinta (Bacigalupo, 1998, p. 56; Barbero, 1957, p. 289; De Simone, 2012, pp. 56-57 y García y Zurita, 2017, p. 379). El propio Fauerbach fue quien redactó el Código Penal de Baviera de 1813, donde se rechaza expresamente la responsabilidad penal corporativa, en su artículo 49:

Si ocurre que la mayoría o la totalidad de los miembros de una comunidad, de un cuerpo profesional o de otro tipo de corporación comete un crimen, solo se considerará culpable a cada uno de los individuos aislados y no a la asociación colectiva. De acuerdo con este principio, los bienes de la comunidad no podrán ser objeto de ninguna pena pecuniaria, de ninguna restitución de daños y perjuicios ni costas. Los bienes particulares de los miembros hallados culpables son los únicos que quedarán sujetos, sin perjuicio de lo que quede prescrito en normas especiales (citado en Martínez, 2018, p. 284). 
En la primera mitad del siglo XIX la teoría dominante de la persona jurídica era la teoría de la ficción de Friedrich von Savigny. Savigny (2005) incide en la importancia de averiguar quiénes pueden ser "sujetos" del derecho y sienta como punto de partida que

todo derecho es la sanción de la libertad moral inherente al ser racional [...], y por esto la idea de persona o sujeto de derecho se confunde con la idea de hombre, pudiéndose formular la identidad primitiva de ambas ideas en estos términos. Todo individuo, y solo el individuo, tiene capacidad de derecho (p. 185).

No obstante, el derecho positivo puede modificar este principio de que todo individuo y solo él tiene capacidad jurídica, negando esta a algunos hombres, como ocurría con los esclavos, o extendiéndola a entes que no son hombres, como sucede con las personas jurídicas (Savigny, 2005, pp. 185186). Así, la capacidad jurídica se ampliaría a sujetos artificiales creados por la simple ficción. En palabras de Savigny (2005), las personas jurídicas son "personas que no existen sino para fines jurídicos, que nos aparecen al lado del individuo como sujetos de las relaciones de derecho" (p. 287).

Savigny (2005) utiliza la palabra persona jurídica en oposición a persona natural, es decir, al individuo, para "indicar que los primeros no existen como personas, sino para el cumplimiento de un fin jurídico, y que si bien otras veces se ha empleado la frase de persona moral" (p. 287), este autor la rechaza por dos motivos: "primero, porque no atiende a la esencia del sujeto que nada tiene de común con las relaciones morales, y segundo, porque aplicada a los individuos designa de ordinario la oposición entre la moralidad y la inmoralidad, lo que nos llevaría a un género de ideas enteramente distinto del presente" (p. 288). En el siglo XIX no solo las personas jurídicas se concebían como una ficción, sino también los niños y los enfermos mentales, que no podían comprender el sentido de la norma y que eran considerados sujetos de derecho del mismo modo que las personas jurídicas, esto es, como sujetos ficticios (Bacigalupo, 2011, p. 67).

Respecto de la cuestión de si las personas jurídicas pueden cometer delitos y ser castigadas con sanciones penales, Savigny (2005) afirma que 
el derecho criminal considera al hombre natural, es decir, un ser libre, inteligente y sensible; la persona jurídica, por el contrario, se encuentra despojada de estos caracteres, siendo solo un ser abstracto capaz de poseer, y que el derecho criminal no podría mezclarse en su esfera de acción; la realidad de su existencia se funda sobre las determinaciones de un cierto número de representantes que, en virtud de una ficción, son consideradas como sus propias determinaciones; y una representación parecida, que excluya la voluntad propiamente dicha, puede tener efecto en cuanto al derecho civil, nunca en cuanto al penal (p. 319).

Savigny estima que los delitos que con frecuencia se imputan a las personas jurídicas se cometen siempre por sus miembros o por sus jefes, esto es, por personas naturales, siendo irrelevante que el interés de la corporación haya servido de motivo o de fin al delito.

La persona jurídica, se dice, no puede cometer delitos, porque cuando esto acontece no obra como tal persona; y esta afirmación es verdadera, no porque dicho modo de actividad sea ilícito, sino en tanto que es extraño a la esencia y al destino especial de la persona jurídica (Savigny, 2005, p. 320).

Como reacción a los postulados de la teoría de Savigny, en la segunda mitad del siglo XIX surgió la teoría de la personalidad real de la asociación o teoría orgánica de Otto von Gierke, la cual, a diferencia de aquella, permitía sostener la RPPJ. Este autor rechaza el presupuesto conceptual sobre el que se basa la teoría de la ficción, trasladando la significación de la cuestión al ámbito social en lugar de la ética. No solo el ser humano puede ser considerado como persona y como sujeto de derecho, pues las personas jurídicas también son personas sociales con la misma capacidad jurídica que los individuos (Bacigalupo, 1998, p. 66 y García y Zurita, 2017, pp. 381-382). Gierke estima que la asociación de personas, al igual que el individuo, constituye "una unidad vital de cuerpo y alma, que puede transformar en un hecho lo que quiere y lo que ha querido" (Bacigalupo, 1998, p. 66, citando la obra de Gierke Das Wesen der Menschlichen Verbände, p. 12). Es decir, la persona jurídica posee una voluntad colectiva que puede, igual que el individuo, realizar acciones con significado social (Cigüela, 2014, p. 51). 
En consecuencia, la consideración de las comunidades organizadas como personas no contradice la realidad, sino que proporciona precisamente una expresión adecuada de la misma. En un discurso universitario pronunciado en Berlín, en 1902, Gierke había afirmado que

la experiencia nos induce a creer en unidades colectivas que obran. La observación de los hechos sociales y la historia de la Humanidad nos demuestran que los pueblos, al obrar, han conformado el mundo y desarrollado la civilización. Derecho, poder, economía, lengua, son fenómenos que no se pueden explicar simplemente por una suma de fuerzas individuales, porque estos no pueden ser producidos parcialmente por individuos aislados. Por esto las comunidades son un todo con una unidad de vida supra-individual, son todos sociales de naturaleza corporal-espiritual (Ferrara, 1929, p. 213, citando la obra de Gierke Das Wesen der Menschlichen Verbände, p. 11 y ss.).

Mientras que la teoría de la ficción de Savigny parte de un concepto prejurídico de sujeto, la teoría orgánica de Gierke parte de los efectos sociales reconocidos por el derecho y considera como sujeto aquel al que dichos efectos le son atribuidos. Gierke intenta demostrar que las personas jurídicas poseen cuerpo y alma y que, por esto, son también personas en el sentido de la teoría de Savigny. En su teoría sitúa tanto al individuo como a la persona jurídica bajo el concepto superior de organismo y le adscribe una vida de cuerpo y alma que se puede expresar en su voluntad (Bacigalupo, 1998, pp. 66-67). La corporación surge espontáneamente, bien por hechos históricos-sociales, bien por decisión libre y voluntaria. En todo caso, existe independientemente de toda intervención del Estado, ya que el reconocimiento estatal no tiene valor constitutivo, sino puramente declarativo, como simple constatación de su existencia (Gierke, 2010, p. XXXIX).

Conforme a esta teoría, la persona jurídica es capaz de querer y de obrar. El derecho atribuye personalidad a los entes colectivos porque los considera portadores reales de una única voluntad, que se manifiesta por medio de órganos, en un sentido análogo a los sujetos individuales. Es la propia persona jurídica, no sus representantes, la que quiere y obra mediante sus órganos, que dan vida a la personalidad inmanente al ente común, siempre que actúen - por supuesto-intra vires y mediante el procedimiento establecido en el acto constitutivo. Como consecuencia lógica de lo anterior, la persona jurídica puede cometer actos ilícitos, con trascendencia civil y 
penal, frente a la clásica teoría de la ficción que se ampara, precisamente, en que no puede delinquir ni pecar. La sanción del ilícito cometido por la persona jurídica puede consistir tanto en penas pecuniarias como en la disolución forzosa de la entidad (Gierke, 2010, p. XL).

$\mathrm{Al}$ igual que Gierke, Aquiles Mestre considera que las personas morales no son seres ficticios, sino que tienen una existencia real. Son personas reales dotadas de conciencia y voluntad propias, distintas e independientes de las que poseen los miembros que las componen, con derechos y deberes también distintos de los de estos. No obstante, mientras que Gierke sostiene que la pena impuesta a la corporación excluye toda pena individual para sus miembros, Mestre cree que se ha de castigar tanto a la persona jurídica que ha cometido el delito como a los individuos responsables que han intervenido en el mismo, puesto que, en caso contrario, se dispensaría el mismo trato a culpables e inocentes (Antón, 1986, p. 175; Cerezo, 2005, p. 69 y Rodríguez y Serrano, 1994, pp. 390-391).

La teoría orgánica de Gierke influyó decisivamente en aquellos autores que a finales del siglo XIX y principios del siglo $\mathrm{xx}$ se posicionaron en contra de la doctrina dominante en aquella época y defendieron la RPPJ. Algunos son: Franz von Liszt, Ernst Hafter y Richard Busch, y, en España, Quintiliano Saldaña y García-Rubio.

Cabe destacar, por último, que en su reciente y minucioso estudio sobre el origen de la frase societas delinquere non potest, Martínez (2018) ha llegado a la conclusión de que la autoría de este aforismo corresponde a Franz von Liszt, quien la habría utilizado por primera vez en la primera edición de su Das Deutsche Reichsstrafrecht, publicada en 1881, con objeto precisamente de refutar este principio. Como indica este autor, la teoría más extendida respecto del origen del brocardo es que se trata de una frase extraída del derecho romano, lo cual se debe probablemente a que está escrita en latín. No obstante, en Roma se reconocía la responsabilidad penal corporativa, por lo que resulta difícil sostener la posibilidad de que un autor de tal tradición jurídica pudiera formular dicha frase. Unido al hecho de que este aforismo no se encuentra en ningún texto romano arcaico, clásico, posclásico o justinianeo, Martínez estima que la clave está en el uso del término societas, que no se emplea para plantear el problema de la responsabilidad penal corporativa hasta el siglo XIX. Salvo alguna excepción, quien lo introduce definitivamente en el debate es precisamente el propio von Liszt en 1881. Mir Puig (2016) parece atribuir a dicha frase origen romano, al afirmar 
que "en Roma se rechazó esta posibilidad - de que las corporaciones puedan cometer delitos-, en base al principio 'societas delinquere non potest", (p. 205). En similares términos se pronuncian Bustos (1994, p. 292), Rodríguez y Serrano (1994, p. 391), López (2010, p. 387) y Luzón (2012, p. 149). Por otra parte, en ocasiones se ha atribuido la autoría del aforismo societas delinquere non potest a Sinibaldo de Fieschi, el papa Inocencio IV. Así sucede, por ejemplo, en Pérez (2014, p. 51), García y Zurita (2017, p. 377), García (2017, p. 97) y Mena (2019, p. 31). Sin embargo, Martínez (2018) sostiene que esta frase no aparece en ninguno de los textos de Inocencio IV y se vuelve a apoyar en la importancia del término societas, puesto que toda la doctrina de Inocencio IV sobre la responsabilidad penal corporativa la hace siempre en términos de universitas, nunca de societas, expresión que en este contexto solo empezó a utilizarse en el siglo XIX (p. 5 y ss.).

Tras negar dichas hipótesis, Martínez concluye que la frase la inventó Franz von Liszt en 1881. Fundamenta su teoría en la ausencia de referencia alguna a este brocardo en textos anteriores a dicho año (incluidas las obras de Otto von Gierke) y en que los trabajos posteriores a 1881, en los que se cita la frase, se nombra también a von Liszt, aunque bien es cierto que sin atribuirle la autoría en ningún momento. Asimismo, señala que von Liszt habría seguido en su manual el mismo sistema de explicación de principios jurídicos que había inventado años antes Anselm von Feuerbach, según el cual, tras desarrollar el principio jurídico en alemán, le da una formulación latina. Ese es el caso de la frase nulla poena sine lege, que ya aparece en la primera edición del manual de Feuerbach de 1801, explicando el principio de legalidad. De este modo, von Liszt utilizó en 1881 este mismo sistema y tras explicar en alemán cuál era la doctrina dominante en materia de responsabilidad penal corporativa, la resumió en una frase construida en latín: societas delinquere non potest. Aunque la autoría del antedicho brocardo correspondería a von Liszt, el holandés Oncko van Swinderen fue el primero en escribir, en 1875, la frase societas delinquere potest, siendo esta la fuente de inspiración de von Liszt al agregar el adverbio negativo non para crear así la frase societas delinquere non potest (Martínez, 2018, p. 5 y ss.). 


\section{CONCLUSIÓN}

La RPPJ tiene su origen en la responsabilidad penal colectiva que fue recogida en textos tan antiguos como el Código de Hammurabi. En el derecho romano podemos hallar supuestos de responsabilidad penal colectiva en la destrucción o pérdida de derechos de ciudades como castigo y en la institución del diezmo. En la Edad Media, aunque los glosadores, al igual que los romanos, no elaboran una teoría de la persona jurídica, consideran que las corporaciones son capaces de delinquir. Los canonistas desarrollan una teoría específica de la corporación eclesiástica entendiéndola como persona y convertida de este modo en el sujeto de derecho, y admiten la capacidad criminal de las corporaciones y la posibilidad de imponerles penas por la comisión de delitos, si bien, gracias fundamentalmente a la obra de Sinibaldo de Fieschi, niegan que puedan ser castigadas con penas espirituales como la excomunión, la cual, por su naturaleza, solo puede aplicarse a los individuos. Por su parte, los posglosadores, entre quienes destaca la figura de Bartolo de Sassoferrato, aceptan la teoría de los canonistas de que la universitas es una persona ficta y sostienen también la posibilidad de que la misma pueda cometer delitos.

A partir del siglo XIX comienza a discutirse realmente la RPPJ y se alzan distinguidos autores como Malblanc y Feuerbach en contra de este régimen de responsabilidad penal. En este siglo la discusión dogmática sobre la naturaleza ficticia o real de la persona jurídica y sus consecuencias en el ámbito penal estuvo protagonizada por Savigny y Gierke. Mientras que la teoría de la ficción de Savigny defiende que las personas jurídicas son sujetos artificiales creados por la simple ficción y no pueden cometer delitos, la teoría orgánica de Gierke profesa que la persona jurídica es capaz de querer y de obrar por medio de sus órganos y, por tanto, también es capaz de cometer aquellos actos delictivos que realice uno de sus órganos en el ámbito de sus competencias y en representación de la misma.

Por consiguiente, puedo concluir este texto reiterando que ha habido que esperar hasta el siglo XIX para encontrar autores que se hayan pronunciado en contra de la RPPJ, proclamando la frase societas delinquere non potest, que habría pronunciado por primera vez von Liszt en 1881, precisamente para rechazar tal principio. En los siglos precedentes ha dominado de forma aplastante la teoría de que las personas jurídicas pueden cometer delitos $\mathrm{y}$, en consecuencia, ser castigadas con sanciones penales (exceptuando la excomunión, inaplicable a las mismas): universitas delinquere et puniri potest. 


\section{REFERENCIAS}

Amalfitano, A. (2014). La responsabilità penale delle persone giuridiche in Europa. Un'indagine teorica e comparatistica per la costruzione di un modello comune [tesis doctoral]. Università degli Studi di Napoli Federico II, Nápoles, Italia. http://www.fedoa.unina.it/9687/.

Antón, J. (1986). Derecho penal (2. a ed.). Akal.

Bacigalupo, S. (1998). La responsabilidad penal de las personas jurídicas. Bosch.

Bacigalupo, E. (2011). Compliance y derecho penal. Aranzadi.

Barbero, M. (1957). ¿Responsabilidad penal de las personas jurídicas? Revista de Derecho Mercantil, (64), 285-336.

Bueno, S. (2014). Las personas jurídicas en el derecho canónico. Facultat de Teologia de Catalunya.

Busato, P. C. (2019). Tres tesis sobre la responsabilidad penal de las personas jurídicas. Tirant lo Blanch.

Bustos, J. (1994). Manual de derecho penal. Parte general (4. ${ }^{\mathrm{a}}$ ed.). Ariel.

Cantarella, E. (2017). Instituciones e historia del derecho romano. Maiores in legibus. Tirant lo Blanch.

Capilla, F. (1984). La persona jurídica: funciones y disfunciones. Tecnos.

Cerezo, J. (2005). Curso de derecho penal español. Parte general. II. Teoría jurídica del delito ( $6 .{ }^{\mathrm{a}}$ ed.). Tecnos.

Cigüela, J. (2014). La culpabilidad colectiva en el derecho penal. Crítica y propuesta de una responsabilidad estructural de la empresa [tesis doctoral]. Universitat Pompeu Fabra, Barcelona, España. https://www.tdx. cat/handle/10803/284236.

D'Alessandro, G. (2015). Struttura e natura della responsabilità da reato degli enti: profili storici, dogmatici, comparati [tesis doctoral]. Università degli Studi di Napoli Federico II, Nápoles, Italia. http://www.fedoa.unina.it/10506/.

D'Urso, F. (2000). Persona giuridica e responsabilità penale. Note storico-giuriche a proposito di recenti riforme. Quaderni Fiorentini per la Storia del Pensiero Giuridico Moderno, 29, 511-550.

De Castro y Bravo, F. (1981). La persona jurídica. Civitas.

De Simone, G. (2012). Persone giuridiche e responsabilità da reato. Profili storici, dogmatici e comparatistici. Edizioni ETS.

Echarri, F. J. (2003). Sanciones a personas jurídicas en el proceso penal: las consecuencias accesorias. Aranzadi. 
Escrihuela, F. J. (2019). La responsabilidad penal de las personas jurídicas [tesis doctoral]. Universidad Católica de Murcia, Murcia, España. http://repositorio.ucam.edu/handle/10952/4013.

Fernández, A. (2019). Derecho romano (3. ${ }^{a}$ ed.). Aranzadi.

Ferrara, F. (1929). Teoría de las personas jurídicas. Reus.

García, A. (2017). La responsabilidad penal de las personas jurídicas en el ordenamiento jurídico español: desarrollo de un modelo de prevención de delitos (compliance program) [Tesis doctoral]. Universidad Europea de Madrid, Madrid, España. https://www.educacion.gob.es/teseo/imprimirFicheroTesis.do?idFichero=IrHFLQRU1sc\%3D.

García, R. J. y Zurita, E. A. (2017). La responsabilidad penal de las personas jurídicas, especial enfoque al caso ecuatoriano. En A. J. Pérez-Cruz (Dir.), Proceso penal y responsabilidad penal de personas jurídicas (págs. 375-399). Aranzadi.

Gierke, O. F. (2010). Teorías políticas de la Edad Media (edición de F.W. Maitland). Estudio preliminar de Benigno Pendás (2. ${ }^{a}$ ed.). Centro de Estudios Políticos y Constitucionales.

González-Varas, A. (2007). Consejo y consentimiento en los órganos colegiados canónicos. Su incidencia en el derecho público secular medieval. Tirant lo Blanch.

Hirsch, H. J. (1993). La cuestión de la responsabilidad penal de las asociaciones de personas. Anuario de Derecho Penal y Ciencias Penales, 46(3), 1099-1124.

López, J. (2010). Tratado de derecho penal. Parte general. Civitas.

Luzón, D. M. (2012). Lecciones de derecho penal. Parte general (2. ${ }^{\text {a }}$ ed.). Tirant lo Blanch.

Marinucci, G. (2008). La responsabilidad penal de las personas jurídicas. Un bosquejo histórico-dogmático. En C. García (Coord.), Estudios penales en homenaje a Enrique Gimbernat. Tomo I (2. ${ }^{\mathrm{a}}$ ed.) (pp. 1173-1200). Edisofer.

Martínez, V. (2018). Responsabilidad penal de las personas jurídicas. La doctrina societas delinquere non potest. $\mathrm{B}$ de $\mathrm{F}$.

Mena, O. G. (2019). La responsabilidad penal de las personas jurídicas. Continental.

Minasola, C. (2015). Il trapianto giuridico dei compliance programs dal sistema statunitense al sistema penale italiano: un approccio storico-comparativo al principio societas delinquere non potest [tesis doctoral]. Università degli Studi di Palermo, Palermo, Italia. http://hdl.handle. net/10447/106047. 
Mir Puig, S. (2016). Derecho penal. Parte general (10. ${ }^{a}$ ed.). Reppertor.

Morales, J. (2000). Notas sobre la evolución histórica de la persona jurídica. Ius Et Praxis, (31), 123-132.

Ortiz de Urbina, I. (2014). Responsabilidad penal de las personas jurídicas: The american way. En S. Mir Puig (Dir.), Responsabilidad de la empresa y compliance. Programas de prevención, detección y reacción penal (págs. 35-88). Edisofer.

Panizo, S. (1975). Persona jurídica y ficción. Estudio de la obra de Sinibaldo de Fieschi (Inocencio IV). Ediciones Universidad de Cizur Menor.

Pérez, J. (2014). Sistema de atribución de responsabilidad penal a las personas jurídicas. Dykinson.

Rodríguez, J. M. y Serrano, A. (1994). Derecho penal español. Parte general (17. ${ }^{\mathrm{a}}$ ed.). Dykinson.

Saldaña, Q. (1927). Capacidad criminal de las personas sociales (doctrina y legislación). Reus.

Savigny, F. K. (2005). Sistema del derecho romano actual. Comares.

Serrano, J. M. (1988). Una aproximación a las fuentes doctrinales de la concepción savigniana de la persona jurídica [tesis doctoral]. Universidad Complutense de Madrid, Madrid, España. https://eprints.ucm.es/53337/. 